\title{
"Lemongrass" and its applications for the treatment of hypertension
}

\author{
Siukan Law, ${ }^{1}$ Chuiman Lo ${ }^{2}$ \\ ${ }^{1}$ Independent researcher; ${ }^{2}$ Department of Chemistry, The Chinese University of Hong Kong, Shatin, New \\ Territories, Hong Kong, China
}

\begin{abstract}
Hypertension (high blood pressure) is the pre-symptom of cardiovascular disease. The number of people living with hypertension has doubled to 1.28 billion and proportionally increased until today. This is a long-term disease and requires continuous monitoring. A traditional Chinese herbal, "Lemongrass", might be a good choice for the mainstay of hypertension. Some library search engines are used, such as SCI/SCIE, PubMed, and Scopus, within ten to twenty years, from 1999-2020. The searched keywords and phrases are "lemongrass", "formulation", "traditional Chinese medicine", "hydrogel", "hypertension", "lemongrass + tea formulation", "lemongrass + hydrogel", "Lemongrass + Hypertension", "Lemongrass + traditional Chinese medicine" etc. This minireview discusses the background of hypertension, lemongrass, research progress, mechanism, lemongrass tea formulations, lemongrass with Traditional Chinese Medicine (TCM) formulations, and the lemongrass hydrogel application in the treatment of hypertension.
\end{abstract}

\section{Introduction}

Hypertension is a global problem with an estimated $26 \%$ of the world's population which has 972 million people, and will be increased to $29 \%$ in $2025 .{ }^{1}$ Some diseases, include stroke, chronic

Correspondence: Siukan Law, E-mail: siukanlaw@hotmail.com

Key words: Lemongrass; traditional Chinese herbal medicine; hypertension.

Conflict of interest: The authors have no conflict of interest to declare.

Availability of data and materials: All data generated or analyzed during this study are included in this published article.

Ethics approval and consent to participate: Not applicable.

Informed consent: Not applicable.

Received for publication: 6 November 2021.

Revision received: 9 December 2021.

Accepted for publication: 9 December 2021.

This work is licensed under a Creative Commons Attribution NonCommercial 4.0 License (CC BY-NC 4.0).

CCopyright: the Author(s),2021

Licensee PAGEPress, Italy

Infectious Diseases and Herbal Medicine 2021; 2:172

doi:10.4081/idhm.2021.172 heart and coronary heart diseases silent killers. It must take effective prevention or treatment measures for hypertension. ${ }^{2}$ In western countries, several antihypertensive drugs such as diuretics, $\beta$ blockers, calcium channel blockers, angiotensin-converting enzyme inhibitors are common to lower blood pressure. However, this is not a long-term treatment as it has adverse reactions, such as dizziness, headaches, and body weakness. ${ }^{3}$ Lemongrass is a natural herbal and doesn't have any side effects, except for people prone to skin and respiratory tract allergic reactions, it may be a more suitable candidate for the treatment of hypertension.

\section{Lemongrass}

It is also known as Cymbopogon citratus. This thrives in warm growing conditions and is a tropical herb packed with a strong citrus flavour. Its leaves have a wide range of medical values, especially for the treatment of hypertension. According to the Traditional Chinese Medicine (TCM) theory, lemongrass belongs to the "Herbs that warm the Interior and expel Cold" category. Its functions are to remove an internal cold and restore " $Q i$ " within the body through liver and lung meridians to improve blood circulation as well as the "Qi" and "body fluids" to nourish the body. $^{4}$

\section{Research progress}

Accumulated evidence has shown that lemongrass (Cymbopogon citratus) elicited relaxation on vascular smooth muscle. The ease of vascular smooth muscle through prostacyclin $\left(\mathrm{PGI}_{2}\right)$ since inhibition of its synthesis by indomethacin resulted in a contraction of hypertensive rat models become low blood pressure. ${ }^{4,5}$ Dzeufiet et al. reported that the aqueous extract of Cymbopogon citratus possessed antihypertensive activity in rats by changing biochemical and oxidative status. It was also protected the liver, kidney, and vascular endothelium against damages to the blood vessels induced by chronic consumption of ethanol and sucrose. ${ }^{6}$ Nambiar et al. indicated the properties of Cymbopogon citratus, including antioxidant and anti-inflammatory for preventing the damage of blood vessels as it increased the level of nitric oxide to help its vasodilation. ${ }^{7}$ Later on in 2018, Somparn et al. discovered the lemongrass water extract consisted of several polyphenolic compounds such as gallic acid, iso-quercetin, quercetin, rutin, catechin, and tannic acid, which decreased serum lipid peroxidation to have the antioxidant and cardiotonic functions. $^{8}$

\section{Mechanism}

Lemongrass consists of phytoactive constituents, including saponins, tannins, flavonoids, alkaloids, and anthraquinones. 
These bioactive components interact with the enzyme or transport systems, especially for the $\mathrm{Na}^{+}-\mathrm{K}^{+}$ATPase and alpha epithelial $\mathrm{Na}^{+}$channel $[\alpha \mathrm{ENaC}]$ mRNA that helps the renal tubules reabsorption of $\mathrm{H}^{+}$. It is effective in acid-base and electrolyte homeostasis to reduce or control the level of blood pressure. ${ }^{9}$ Rhiouani et al. reported that saponin regulated the blood pressure and renal function in hypertensive rats through the $\mathrm{Na}^{+}-\mathrm{K}^{+}$ATPase channel. ${ }^{10}$ Jouad et al. also identified that flavonoids in lemongrass increased the concentrations $\mathrm{Na}^{+}, \mathrm{K}^{+}$, and $2 \mathrm{Cl}^{-}$of a urinary system to influence the salt and water transport in renal tubules. ${ }^{11}$ Chen et al. discovered the inhibitory effect of saponins on the ReninAngiotensin-Aldosterone System (RAAS) to maintain the level of blood pressure, balance the acid-base condition, and control the fluid volume in the body. ${ }^{12}$ The bioactive components in lemongrass are contributed to the $\mathrm{Na}^{+}-\mathrm{K}^{+}$ATPase and alpha epithelial $\mathrm{Na}^{+}$channel $[\alpha \mathrm{ENaC}]$ associated with the body metabolism for the prevention of hypertension.

\section{Lemongrass tea formulation}

Nowadays, lemongrass is formulated as a herbal tea drink to prevent and treat hypertension. The lemongrass tea recipe is simple. Cut the lemongrass in 1 or 2 inches and add 5 cups of water, a few mints with jiggery for boiling in 5 to 10 minutes. In 2012, Ullah et al. reported lemongrass tea effectively reduced high blood pressure and decreased heart rate. ${ }^{13}$ Koner et al. identified lemongrass tea as antioxidants to detoxify and clean the toxic substance within our body. It regulated blood circulation and lowered blood pressure by the potassium ion from lemongrass tea. This also limited cholesterol absorption and purified it in the liver to prevent hypertension and heart diseases. ${ }^{14}$

However, excess consumption of lemongrass tea might influence the homeostatic mechanisms such as balancing the acid-base and electrolytes of body fluid. ${ }^{9}$ Some exhibit potential side effects, including frequent urination and allergic reactions. ${ }^{15}$ Ekpenyong et $a l$. identified that if the lemongrass tea is at a high dose or as a prolonged treatment, the estimated Glomerular Filtration Rate (eGFR) could be decreased and followed by a decline in the other renal function indices. ${ }^{16}$

\section{Lemongrass TCM formulation and clinical study}

In the TCM formulation, lemongrass efficacy relieves wind from the surface, removes blood stasis, and dredge collaterals. It is used in the cure of cold, headache, stomach pain, diarrhea, rheumatic arthralgia, bruises, and to regulate blood pressure. The dosage of lemongrass for oral administration is about $3-9 \mathrm{~g}$ in Chinese medicine decoction.

Lee et al. reported lemongrass suppressed the sympathetic nervous system activity and blood pressure in a clinical study of 24 young male adults. Participants drank $180 \mathrm{~mL}$ of lemongrass tea for two weeks every morning, and their average blood pressure dropped from $153 / 90 \mathrm{mmHg}$ to $141 / 82 \mathrm{mmHg} .{ }^{17}$

\section{Lemongrass hydrogel}

Could lemongrass be suitable for synthesizing hydrogel? De Matos et al. indicated hydrogel integrating lemongrass-loaded nanosponges with an enhanced antifungal effect in vitro or in vivo. ${ }^{18}$ This nanosponges delivery system study may also act as a carrier of an anti-hypertensive drug in the future. Earlier in 2013, Campos et al. reported lemongrass antioxidant properties to prevent endothelial dysfunction associated with an oxidative imbalance promoted by different oxidative stimuli. It decreased the Reactive Oxygen Species (ROS) production and inhibited the vasoconstrictions induced by thromboxane A. ${ }^{19}$

Lemongrass hydrogel synthesis possibly relates to natural polymers such as alginate, cellulose derivatives, and chitosan. It depends on the biocompatible and biodegradable properties. The nanoscale of lemongrass as carriers for a delivery system includes Polycaprolactone (PCL), Polylactic Acid (PLA), polyurethane, and Polyvinyl Pyrrolidone (PVP) because of the good tissue compatibility, solute permeability, and excellent electro-spinnability. ${ }^{20}$

\section{Conclusion}

The above information demonstrates that lemongrass and its TCM formulations are possible candidates for the treatment of hypertension. Herbal tea is not well-regulated and formulated in TCM and its application for the hydrogel. However, this must pay attention to the dosage of lemongrass in daily life and further develop it into hydrogel. Much more works need to be done as the previous investigations are inconclusive, such as qualitative and quantitative assessments of lemongrass in the human body.

\section{References}

1. Mills KT, Stefanescu A, He J. The global epidemiology of hypertension. Nat Rev Nephrol 2020;16:223-37.

2. Singh S, Shankar R, Singh GP. Prevalence and associated risk factors of hypertension: A cross-sectional study in urban Varanasi. Int J Hypertens 2017;2017:5491838.

3. Olowofela AO, Isah AO. A profile of adverse effects of antihypertensive medicines in a tertiary care clinic in Nigeria. Ann Afr Med 2017;16:114-9.

4. Ekpenyong CE, Akpan E, Nyoh A. Ethnopharmacology, phytochemistry, and biological activities of Cymbopogon citratus (DC) Stapf extracts. Chin J Nat Med 2015;13:321-37.

5. Devi RC, Sim SM, Ismail R. Effect of Cymbopogon citratus and Citral on vascular smooth muscle of the isolated thoracic rat aorta. Evid Based Complement Alternat Med 2012;2012:539475.

6. Dzeufiet PD, Mogueo A, Bilanda DC, et al. Antihypertensive potential of the aqueous extract which combine leaf of Persea americana Mill. (Lauraceae), stems and leaf of Cymbopogon citratus (D.C) Stapf. (Poaceae), fruits of Citrus medical L. (Rutaceae) as well as honey in ethanol and sucrose experimental model. BMC Complement Altern Med 2014;14:507.

7. Nambiar VS, Matela H. Potential Functions of Lemon Grass (Cymbopogon citratus) in Health and Disease. Int J Pharm 2012;3:1035-43.

8. Somparn N, Saenthaweeuk S, Naowaboot J, et al. Effect of lemongrass water extract supplementation on atherogenic index and antioxidant status in rats. Acta Pharm 2018;68:18597.

9. Ekpenyong CE. Lemongrass tea consumption and changes in Acid-Base Balance and Electrolyte homeostasis. Arch Food Nutr Sci 2018;2:41-51.

10. Rhiouani H, Settaf A, Lyoussi B, et al. Effects of sap on ins. from Hemiaria glabra on blood pressure and renal function in spontaneously hypertensive rats. Therapie 1999;54:735-9. 
11. Jouad H, Haloui M, Rhiouani H, et al. Ethnobotanical survey of medicinal plants used for the treatment of diabetes, cardiac and renal diseases in the North centre region of Morocco (FezBoulemane). J Ethnopharmacol 2001;77:175-82.

12. Chen M, Long Z, Wang Y, et al. Protective effects of saponin on a hypertension target organ in spontaneously hypertensive rats. Exp Ther Med 2013;5:429-32.

13. Ullah N, Nazir A, Anwar S, et al. Effect of Lemongrass and green tea on blood pressure and heart rate. Medical Forum Mon 2011;22:11-3.

14. Koner S, Dash P, Priya V, Rajeswari VD. Natural and artificial beverages: Exploring the pros and cons. Natural Beverages 2019;13:427-45.

15. Mirghani MES, Liyana Y, Parveen J. Bioactivity analysis of lemongrass (Cymbopogan citratus) essential oil. Int Food Res J 2012;19:569-75.

16. Ekpenyong CE, Daniel NE, Antai AB. Effect of lemongrass tea consumption on estimated glomerular filtration rate and creatinine clearance rate. J Ren Nutr 2015;1:57-66.
17. Lee MS, Lee J, Park BJ, Miyazaki Y. Interaction with indoor plants may reduce psychological and physiological stress by suppressing autonomic nervous system activity in young adults: a randomized crossover study. J Physiol Anthropol 2015;34:21.

18. De Matos SP, Teixeira HF, De Lima ÁAN, Veiga-Junior VF, Koester LS. Essential Oils and Isolated Terpenes in Nanosystems Designed for Topical Administration: A Review. Biomolecules 2019;9:138.

19. Campos J, Schmeda-Hirschmann G, Leiva E, et al. Lemongrass (Cymbopogon citratus (D.C) Stapf) polyphenols protect human umbilical vein endothelial cell (HUVECs) from oxidative damage induced by high glucose, hydrogen peroxide and oxidised low-density lipoprotein. Food Chem 2014; $151: 175-81$.

20. Chiriac AP, Rusu AG, Nita LE, et al. Polymeric carriers designed for encapsulation of essential oils with biological activity. Pharmaceutics 2021;13:631. 